\title{
The new landscape of global agriculture
}

\author{
Johann Kirsten
}

\section{Introduction}

There are strong indications and evidence that the agricultural and food system as well as the rural areas across the world are experiencing major change. Increased urbanization and the increased affluence in emerging economies combined with the demand for agricultural commodities for biofuels is changing the landscape of global agricultural and food systems and rural landscapes as we used to know it. The recent crisis in the global financial system and the sharp volatility in food prices also provides further evidence that the global agricultural landscape is indeed likely to be totally different.

Associated with all of this are changes in the mesa environment of agriculture, such as the way that donor aid to agriculture and agricultural R\&D is channeled; the increased share of the private sector in agricultural $\mathrm{R} \& \mathrm{D}$; and the increased use of information and communication technologies (ICT) in agricultural production and agricultural markets. Finally, the agricultural sector is still strongly linked with the ecological and environmental resource base, which suggests that environmental issues and climatic threats are still relevant issues in this new landscape. It is therefore fitting that the conference theme of the 27th International Conference of Agricultural Economists that took place in Beijing in August 2009 was "The New Landscape of Global Agriculture."

The Beijing conference provided an ideal opportunity for members of the International Association of Agricultural Economists (IAAE) to deal with the smorgasbord of challenges, new realities, and dimensions of world agriculture. At the same time, it created the opportunity to think about the adjustments needed in the discipline of agricultural economics in order to address these emerging and likely more complex issues. Among other things, this calls for an expansion of the traditional toolkit of agricultural economists and to become much more multidisciplinary in order to ensure that agricultural economists continue to play an important role in this changing and complex landscape and to prevent the "extinction" of the discipline, as Joachim von Braun warned us in 2003 (Von Braun, 2005).

The need for more interdisciplinary work does, however, expose significant barriers to this proposed interdisciplinary exchange. These barriers are caused in large part (but not exclusively) by our ignorance of other disciplines' methods, theories, and empirical findings; by language/jargon; and by disciplinary arrogance. With this in mind, it was decided to depart from standard practice by inviting a number of keynote speakers from outside the discipline of agricultural economics to speak at our conference. This interesting experiment paid off, since these speakers helped to stimulate the debate and introduce the issues to be discussed in the other sessions of the conference.

Despite the focus on disciplinary matters, the conference theme naturally opened the opportunity to include keynote papers on the financial and food crises to address some of these more recent issues (including the debate on biofuels) that are shaping agriculture globally. We cannot be silent on these issues and papers prepared on these topics presented important reviews of the literature and challenged our discipline with further research questions.

The conference was appropriately launched by the presidential address of David Colman. He challenged 
some stylized facts about agriculture's terms of trade. These facts contributed to agriculture being seen as a declining sector, and one that should receive less policy priority than others in efforts to promote growth. Colman argues that this position has not always been the case, and there are many, particularly at the current juncture in global economic change, who now argue that agriculture needs to move up the policy agenda. His paper does not seek to address the full sweep of arguments for giving higher priority to agriculture and the rural sector, but rather examines whether the evidence for a secular decline of its terms of trade actually exists, and whether there are systematic biases in the way analysis of this question has been conducted. As such, the paper links up very well with the Leonard Elmhirst lecture of Alain de Janvry in trying to make a case against the neglect of agriculture.

Alain de Janvry's Elmhirst lecture provides a further argument or appeal for acknowledging the role of agriculture for development. In the context of the changing world agricultural landscape, his lecture reminds us that the classical paradigm of agriculture on the road to industrialization, which prevailed in economic thought in the 1960s and 1970s, no longer matches this dramatically changed rural and agricultural landscape nor the much broadened development objectives. Various crises and opportunities, which shaped the new global agricultural landscape, have also prompted the emergence of what de Janvry calls a "new paradigm of agriculture for development." Conditions are currently favorable for implementing this new paradigm. This is the result of agriculture's high public profile currently, the political pronouncements of concern with food security in response to electoral demands and popular discontent, and attractive investment opportunities for producers with high prices and new dynamic markets.

\section{New driving forces in emerging economies shaping the global agricultural landscape}

The first plenary session of keynote papers explored the driving forces from the largest emerging markets such as India, China, Brazil, the former republics of the Soviet Union (the KRU countries), and Africa that could shape the global agricultural landscape. Many of these countries and regions have experienced high economic growth in recent years and also some interesting structural changes.
Ashok Gulati and Kavery Ganguly paper tracks the revolutionary changes in the Indian agricultural sector from the Green Revolution, through the "White Revolution" in the dairy industry to the recent biotechnology revolution in the crop sector. In all these changes, technology, institutions, and markets have had a very important role to play. The public sector's role was also significant. The corporate private sector has recently contributed by altering the complexion of the Indian agri-system through notable changes in organized food processing and retailing. Despite continued high poverty levels, India is now in a much better position to deal with the food security issues than it was when it launched economic reforms. On the other hand, the emerging structural changes in the agri-system are in favor of the growth of high-value agriculture.

The rapid changes in rural areas and the agricultural sector of China are well-documented, but the paper by Jikun Huang, Jun Yang, and Scott Rozelle provides additional evidence of how, over the course of the economic reform period in China, both rural and urban incomes have increased. The rising income has also been associated with a substantial reduction in poverty and a significant improvement in food security, and has thus been one of the most important driving forces shaping the agri-food system in China. China's experience also shows that institutional innovation (particularly land tenure), technological changes, and market reform and infrastructure development are critical to the improvement of the nation's food security. The main implications of China's rapid economic growth are that China's growth will provide more opportunities than challenges to the rest of the world while clearly having an impact on the shape of the global agricultural landscape.

Although domestic driving forces and changes within these emerging economies are important factors shaping the global agricultural landscape, global forces also shape the domestic agricultural and food systems of many countries. This is well illustrated by Decio Zylbersztajn in his discussion on the changes in Brazil. He argues that the driving forces act locally as well as globally and are not independent from each other. Each driver imposes the need for new institutional rules, and it is for this reason that one can also argue that the high economic growth, rapid urbanization, and changing consumption patterns emerging in many countries are the visible signals of a much deeper 
global adjustment rooted in how societies are dealing with institutions and institutional change.

The world grain trade has seen some interesting changes over the last decade, largely as a result of the increased importance of the major former Soviet republics (Kazakhstan, Russia, and Ukraine) in the world grain market. The paper by William Liefert, Eugenia Serova, and Olga Liefert illustrates the two main developments: (1) this region has become a large grain exporter, especially of wheat and barley and (2) Russia has become a big agricultural importer, especially of meat. The authors argue that these trends should continue for the next decade. However, policies to expand the livestock sector could mitigate these developments, as increased domestic meat production would reduce both meat imports and result in surplus feed grain for export.

Promising changes in African agriculture are also visible. Akinwumi Adesina reports in his paper that better governance in most countries and a greater commitment to agricultural development through the Comprehensive Africa Agriculture Development Programme (CAADP) has improved incentives for African farmers in many countries, contributing to substantial agricultural growth. Higher urban incomes have also stimulated effective demand for food and, in combination with foreign investment in agroprocessing and retailing, are shaping new agri-food systems in these countries. Advances toward solving Africa's food crisis could, however, be negated by poor infrastructure, climate change, and poor policy decisions by governments.

\section{The new economics and politics of market power in the agricultural and food industry}

It is sometimes argued that agricultural economists' work on the market power of agribusiness is one of the areas where "mischief has been done." The papers prepared for the second plenary session illustrated the complexity of analysis in market power studies in food supply chains, and highlighted the type of work agricultural economists can do to correct this perception. With increasingly concentrated agricultural and food systems and the increasing dominance of large supermarket chains in national and global food chains now an important feature of the changed agricultural landscape, there is a demand for more economic analysis of this issue and also a need for more evi- dence of the economic effects of the abuse of market power.

Ronald Cotterill's paper provides an interesting insight into the world of antitrust cases in the food industry, and illustrates how antitrust enforcement concerning monopolies, mergers, and cartels is converging across all market-oriented economies in the world. The role of empirical economic analysis, however, has not converged as rapidly as the conceptual model because different countries have different enforcement institutions and strategies. Despite the complexities of these cases, Cotterill maintains that agricultural and applied economists who are trained in empirical industrial organization and econometric methods are ideally suited for antitrust work. However, in addition to technical research skills, one must be very adept at analyzing information gathered from an industry, formulating models that address the alleged conduct, and communicating with noneconomists such as lawyers, judges, and juries. His point is well illustrated by the Peter Davis and Alan Reilly paper, which documents the recent Competition Commission investigations in the conduct of the large food retailers in the United Kingdom. The paper not only illustrates the important economic analyses that can play a role in such investigations but also shows how it informs the design of remedies to deal with the perceived abuse of market power by supply chain actors. The Johan Swinnen and Anneleen Vandeplas paper takes a slightly different angle by investigating the role of concentration and market power in international food supply chains. They argue that, while there appears to be agreement in the literature that consolidation in the food industry is a feature of our new landscape, the impact of this concentration on efficiency and rent distribution is more nuanced and complex than often claimed. Their paper develops a model that explicitly takes into account market imperfections and contract enforcement problems in supply chains. This model then illustrates that increased concentration is likely to benefit farms by improving contract conditions, but may hurt them as contract enforcement becomes more complicated.

\section{Global public goods and 21st century agriculture}

The world economy of the 21 st century is now much more open and integrated than before. Events in one 
area of the globe often unleash repercussions that are felt around the world (as was illustrated by the recent financial and food crises). As a result Global Public Goods, defined as goods with benefits that extend to all countries, people, and generations are central to this new globalized society. Those that are critical to the agricultural systems of the future include climate stability, environmental sustainability, food safety, disease control, and recently the more holistic concept of "biosecurity." For all of these, knowledge is a necessity and here international agricultural research, usually also defined as a global public good, still needs to play a critical role. Most of these public goods are intangible and are more "conditions" than concrete things. Their provision is thus difficult to monitor and verify, and so is especially prone to running off course.

The purpose of the keynote papers in the third plenary session was to highlight the importance of global public goods in the new landscape of global agriculture and also to highlight the changes and challenges related to each of them. The papers addressed: (1) climate stability (the paper by John Quiggin), (2) international agricultural research (the paper by Prabhu Pingali), and (3) a stable financial system (the paper by Justin Lin and Will Martin) as the three "global public goods" to be discussed in this session. Including the "financial system" as a public good was done at a late stage of the development of the program when the financial crisis unfolded, illustrating the importance of the global financial system for global agriculture and development. Prabhu Pingali not only highlights the public good nature of international agricultural research in his paper but also illustrates how the changing aid flows to international agricultural research could in itself change the way this "good" will be provided in the near future. John Quiggin illustrates the public good nature of "climate" and also makes the case for how agriculture can provide public goods by contributing to climate stability.

\section{The new landscape and the need for an extension to the agricultural economics toolkit}

The purpose of the papers in this session was to illustrate how other related social science disciplines and new methods can be of value to agricultural economists as they start to deal with more complex socioeconomic and sociopolitical and environmental problems in the new landscape of global agriculture. Some of these problems are more complex, requiring different modeling approaches; others demand more understanding of sociology, social capital, and political science; and yet others demand a move away from the standard assumptions of economic theory. The three papers in this session therefore addressed fairly diverse topics but are in themselves useful reference points for the future work of agricultural economists.

The 2009 Nobel Laureate Elinor Ostrom opened this session with a paper on collective action problems that pervade all societies as well as ecological systems used by humans. In dealing with these collective action problems, she questions the model of rationality as a useful model in explaining behavior and outcomes in competitive market settings and as a universal theory of human behavior. The paper goes on to examine how a theory of boundedly rational, normbased human behavior is a better foundation for explaining collective action than a model of maximizing material payoffs to self. If one posits that individuals can use reciprocity and reputations to build trust in dilemma situations, then one can begin to explain both successful and unsuccessful efforts to overcome social dilemmas through collective action. The points made by Ostrom could have profound implications on how we, as agricultural economists, think about modeling behavior if we really want to address important social dilemmas.

Gilles Allaire's paper links nicely with Ostrom regarding the questioning of orthodox theory. He explains how Economic Sociology and Convention Theory is more useful in understanding markets and appreciating markets as social constructs, which are governed by institutions and social orders. This adjustment in the analytical framework to study markets and especially food markets is useful in unpacking the various dimensions of "quality" in food products and illustrating that "quality" is an institution, which is shaped by society and by culture.

Anastasios Xepapadeas concluded this session by illustrating the value of new modeling techniques used to model more complex systems, such as ecological systems that are not characterized by linear dynamics. He argues that for a realistic representation one would require adoption of complex nonlinear dynamical systems with characteristics encountered in 
complex adaptive systems. In this respect, adequate modeling should include and combine elements such as strategic interactions among economic agents, nonconvexities induced by nonlinear feedbacks, separate spatial and temporal scales and modeling of spatiotemporal dynamics, and allowance of alternative time scales.

\section{Energy, advances in technology, and food prices}

The papers in this session covered three major issues that have all in a different way contributed to a totally different agricultural landscape: bioenergy, ICT, and commodity and food prices.

First, the shift to bioenergy production has been responsible for a strong integration of agricultural commodity markets and energy markets. The paper by Wallace Tyner explains the evolving links between energy and agricultural markets, and illustrates how there emerged a strong link between crude oil, gasoline, and corn prices following the ethanol boom in the United States during 2006-2008. The paper explores the drivers in these markets as well as other major issues facing the corn ethanol industry in the United States, such as the "blend wall."

Second, ICT has had a dramatic impact on the marketing of output in the forestry, fishery, and agricultural sectors in developing countries. Robert Jensen identifies five primary impacts: two direct channels (efficient arbitrage and reduced market power) and three channels following from the first two (supply responses, reduced use of transportation, and reduced price variability). He confirmed this through citing empirical studies that have found significant gains in consumer and/or producer welfare, particularly when there was no previous source of information available. Just as importantly, any gains observed are likely to be permanent, since they represent a structural improvement in the efficiency of market functioning.

In the final keynote paper of the Beijing 2009 conference, Derek Headey, Sangeetha Malaiyandi, and Shenggen Fan revisit the food price crisis of 2008 and use some hindsight to show what we know now and what we still do not know about the food price crisis. Their analysis of the global food price crisis reminds us why agricultural policy issues are being given considerably greater attention, why agriculture has emerged from a long period of neglect by governments globally, and why the global landscape of agriculture is indeed different today.

This, the 27th International Conference of Agricultural Economists, was the first conference of the IAAE to be hosted in China. The support from the Chinese Government and the wonderful and slick organization of the local organizing committee, combined with this set of thought-provoking plenary papers mentioned above, made this a landmark event in the history of IAAE. The conference proceedings were also enriched by solid contributed papers (some were published in Agricultural Economics, volume 41: 3-4), and interesting and well-designed panel sessions and discussion groups.

\section{Reference}

Von Braun, J., 2005. Agricultural Economics and Distributional effects. Agric. Econ. 32, 1-20. 